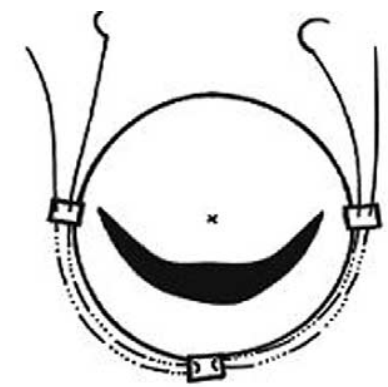

A

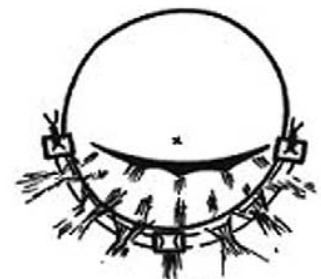

B
Figure 1. Technique of posterior annular plication used in this case.

\section{References}

1. Zaroff JG, Rosengard BR, Armstrong WF, Babcock WD, D'Alessandro A, Dec GW, et al. Consensus conference report: maximizing use of organs recovered from the cadaver donor: cardiac recommendations. Circulation. 2002;106:836-84.

2. Antunes MJ, Vieira H, Ferrão de Oliveira J. Open mitral commissurotomy: the "golden standard." J Heart Valve Dis. 2000;9:472-7.

3. Massad MG, Smedira NG, Hobbs RE, Hoercher K, Vandervoot P, McCarty PM. Bench repair of the donor mitral valve before heart transplantation. Ann Thorac Surg. 1996;61:1833-5.

4. Michler RE, Camacho DR. Ex-vivo mitral valve repair prior to orthotopic cardiac transplantation. Ann Thorac Surg. 2002;73:962-3.

5. Risher WH, Ochsner JL, Van Meter C. Cardiac transplantation after donor mitral valve commissurotomy. Ann Thorac Surg. 1994;57:221-2.

\title{
Salmonella infection in an anterior mediastinal mass
}

Yvonne M. Carter, MD, ${ }^{a}$ Lamia Shagrun, MD, ${ }^{b}$ Harvey Klein, MD, ${ }^{b}$ Jeffrey Katz, MD, ${ }^{c}$ and David M. Jablons, MD, ${ }^{a}$ San Francisco, Calif

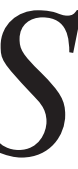

almonella infection occurs through fecal-oral transmission and usually appears in the biliary tract in the rare instance that it is extraintestinal. Thoracic Salmonella infection is rare $^{1-3}$ and has never been reported in the thymus. One case attributes a Salmonella thyroid abscess to the immunosuppressive therapy for myasthenia gravis. ${ }^{4}$ There has been only one previous report of thymic abscess in an adult in the literature. ${ }^{5}$ We report the first description of a Salmonella bacteremia associated with a thymic abscess within a thymoma.

\section{Clinical Summary}

Six years before presentation, a 55-year-old woman was found to have a large, anterior mediastinal mass on routine chest radiography. It was presumed to be a thymoma at that time, and she declined further diagnostic or therapeutic intervention.

At the time of presentation, the patient reported a 3-day history of fevers, polyarthralgias, rigors, chills, and pleuritic chest pain. She denied any symptoms suggestive of myasthenia gravis. Her

\footnotetext{
From the Division of Thoracic Surgery, ${ }^{\mathrm{a}}$ the Department of Pathology, ${ }^{\mathrm{b}}$ and the Department of Anesthesiology, ${ }^{\mathrm{c}}$ University of California, San Francisco Medical Center, San Francisco, Calif.

Received for publication March 18, 2004; accepted for publication April 6, 2004.

Address for reprints: David M. Jablons, MD, Thoracic Surgery, UCSF Medical Center, 505 Parnassus Ave, Box 0118, San Francisco, CA 94143 (E-mail: JablonsD@ @urgery.ucsf.edu).

J Thorac Cardiovasc Surg 2005;129:228-30

$0022-5223 / \$ 30.00$

Copyright $\odot 2005$ by The American Association for Thoracic Surgery doi:10.1016/j.jtcvs.2004.04.042
}

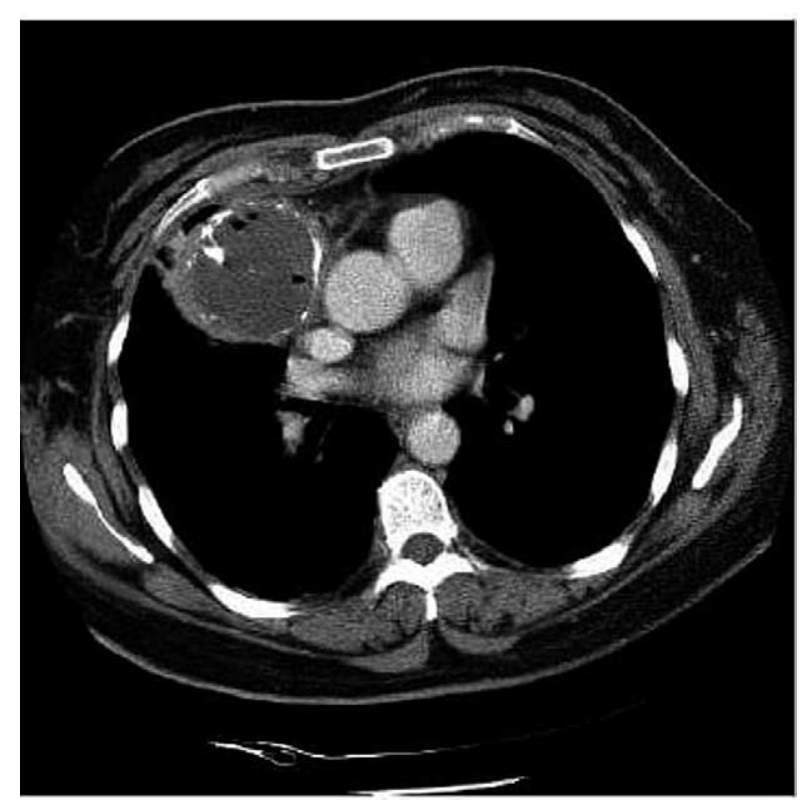

Figure 1. Chest computed tomographic scan of the $8 \times 10-\mathrm{cm}$ calcified mass in the anterior superior right mediastinum.

medical history included type II diabetes mellitus and leukocytosis and thrombocytosis of unknown cause.

Significant clinical findings on admission were a temperature of $101.7^{\circ} \mathrm{F}$ and a blood pressure of $90 / 50 \mathrm{~mm} \mathrm{Hg}$. Her white blood cell count was $24,600 / \mu \mathrm{L}$, with $66 \%$ polymorphonuclear cells and $17 \%$ bands. With prophylactic antibiotics, her white blood cell count decreased to $13,000 / \mu \mathrm{L}$; however, she continued to have 

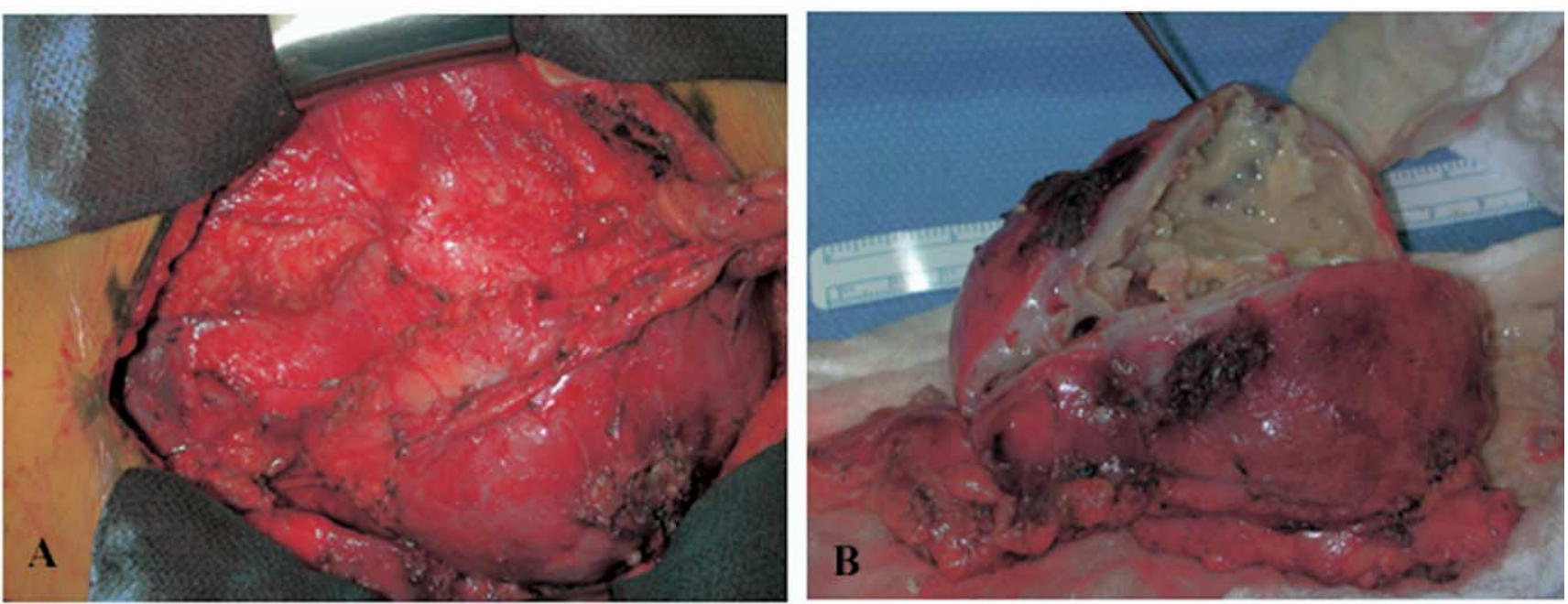

Figure 2. A, Well-encapsulated mass arising from the lower lobe of the right thymus within the right pulmonary hilum. Dense inflammatory reaction with adhesions to the pericardium and middle and lower lobes of the lung. B, Bilobed specimen.
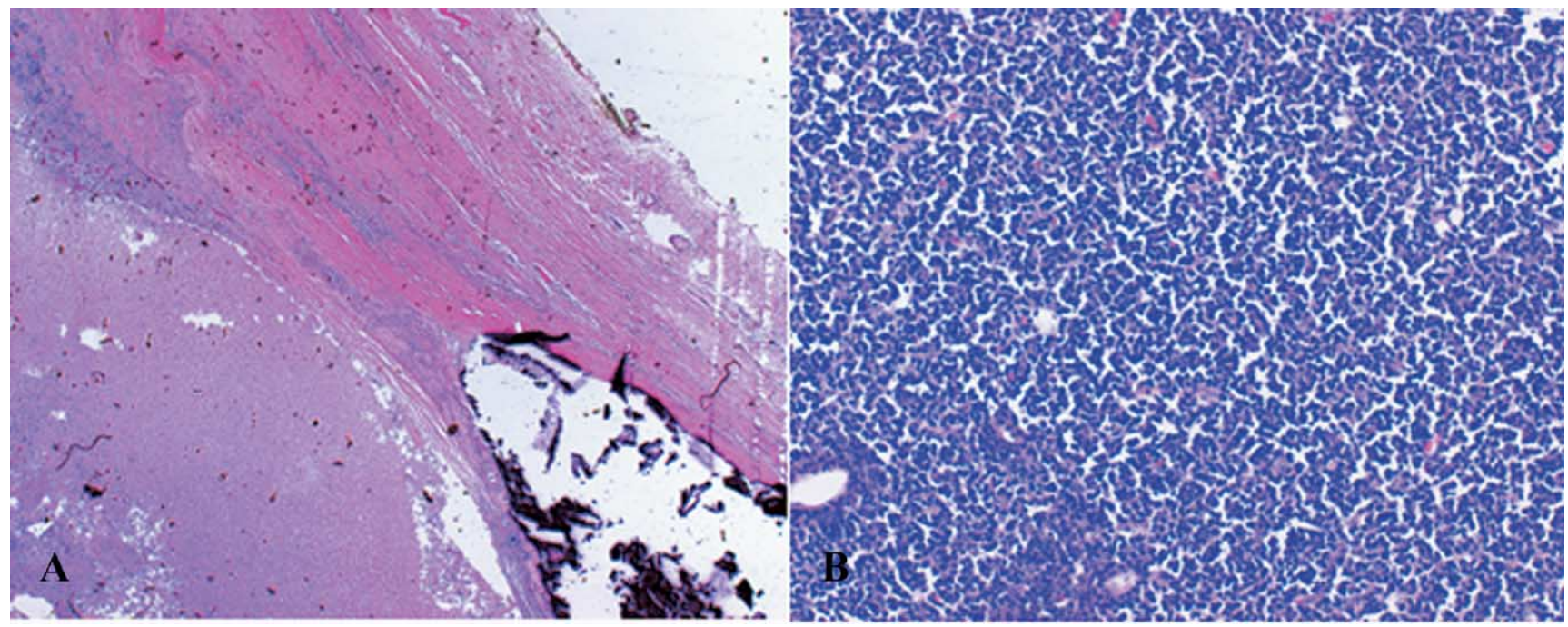

Figure 3. Microscopic examination. Lymphocytic infiltrate consisting of mostly $T$ cells with rare B cells. No capsular invasion was noted.

fevers (highest temperature, $103.6^{\circ} \mathrm{F}$ ), with associated hypoxemia and hypotension. Cultures of blood drawn at the time of admission grew Salmonella, and consequently, she was treated with intravenous ceftriaxone.

Repeat chest radiography 6 days after admission revealed a new air-fluid level within the mediastinal mass. She underwent computed tomography-guided percutaneous catheter drainage of the mass (Figure 1), with an initial return of $230 \mathrm{~mL}$ of clear yellow fluid. The fluid cultures also grew Salmonella; however, the results of stool cultures were negative. Abdominal ultrasonography and computed tomography did not reveal extraintestinal sites of infection. With continued catheter drainage, the fevers resolved, and her white blood cell count stabilized at $11,000 / \mu \mathrm{L}$ with enteral antibiotics.
With resolution of her sepsis, the patient underwent mediastinal exploration and resection of the mass through a median sternotomy. A small right pleural effusion and loculated empyema was found in addition to a mass compressing the right hilum (Figure 2, A). En bloc resection mandated wedge resection of the medial aspect of the lower lobe and was accompanied by decortication and irrigation. The phrenic nerve and internal thoracic artery were preserved. Transection of the surgical specimen allowed for appreciation of the calcified septae and purulent fluid (Figure 2, B). Her postoperative course was uncomplicated, and she was discharged home on postoperative day 3 .

Microscopic analysis of the mass demonstrated a benign (type B) thymoma (Figure 3) with associated fibrosis. No organisms were identified in the specimen. There was no evidence of micro- 
scopic capsular invasion. On follow-up, she remains asymptomatic, with no recurrence of the mass.

\section{Discussion}

Previous reports on the management of Salmonella-induced mediastinitis have used either drainage (percutaneous or surgical) ${ }^{2,3}$ or surgical exploration of the mediastinal mass. ${ }^{1,5}$ Snider and colleagues ${ }^{1}$ concluded that surgical exploration was the procedure of choice because it was both diagnostic and therapeutic. However, they identified a recurrent calcific mass on follow-up radiologic studies in their patient.

Thymomas are the most common neoplasm in the anterior mediastinum and originate from the thymic epithelial cell. Most patients are asymptomatic, but the most common symptoms are due to compression of adjacent structures or myasthenia gravis. The prognosis with resection is excellent for early encapsulated lesions but is relatively poor when local invasion is identified. Complete resection is the critical factor in determining long-term survival. Microscopic invasion is identified in $20 \%$ of resected thymomas that appear encapsulated on gross examination. ${ }^{6}$ Currently, it is uncertain whether neoadjuvant chemotherapy is beneficial in preventing recurrence or prolonging survival in patients with capsular invasion.

We suggest a multimodality approach to the infection mediastinal mass. Computed tomography provides an accurate definition of the mass, indicates malignant potential (ie, local extension into fascial pleura, lung, or pleural space) in the case of a thymoma, and allows for surgical planning. In the case of severe sepsis, percutaneous catheter drainage provides stabilization for surgical resection. Surgical intervention should include en bloc resection of the thymus, decortication, and copious irrigation. This approach adequately treats the infectious process, as well as any potential neoplasms.

\section{References}

1. Snider JM, Hannah H, McNabney WK, Pemberton LB. Salmonella mediastinal abscess. Ann Thorac Surg. 1993;56:556-8.

2. Marsh MD, Amorosa JK, Abassi M, Nasher JL, Gross SC, Alcid DV. Salmonella mediastinitis—a rare disease. Comput Radiol. 1984;8:375-7.

3. Tilly H, Gardembas M, Barry M, Gray C, Monconduit M, Piquet H. Salmonella infection in hairy cell leukemia: report of a case. Am J Hematol. 1985;19:423-5.

4. Zimmermann CW, Lingenfelser T, Melms A, Jakover B. Abscess of the thyroid gland caused by Salmonella enteritidis in immunosuppressive treatment of generalized myasthenia gravis with thymoma. Nervenarzt. 1990;61(10):626-8.

5. Rubinstien E, Slavin J. Thymic abscess with bacteremia and manubriosternal pyarthrosis in a geriatric patient. Chest. 1993;103:962-4.

6. Kornstein MJ, Curran WJ Jr, Turrisi AT, et al. Cortical versus medullary thymomas: a useful distinction? Hum Pathol. 1988;19: $1335-9$. 